\title{
ASAPHOBELIS PHYSONYCHUS SIMON: DESCRICÃO DA FÊMEA E NOVAS CONTRIBUICOÕES PARA O CONHECIMENTO DO MACHO (ARANEAE, SALTICIDAE)
}

\author{
Arno Antonio Lise ${ }^{1}$ \\ Augusto Braul Junior ${ }^{1,2}$
}

\begin{abstract}
ASAPHOBELIS PIYSONYCHUS SIMON: IESCRIPTION OF THE FEMALE AND NEW CONTRIBUTIONS TO THE KNOWLEgment OF THE MALE (ARANEAE, SaltiCiI)AE). The female of Asaphobelis physonychus Simon, 1902 is described for the first time. Some new comments about the male are provided and the palpus is illustrated.

KEY WORDS. Araneae, Salticidae, Asaphobelis. Neotropical Region, taxonomy
\end{abstract}

Em recentes coletas efetuadas em Guaiba, Rio Grande do Sul, no interior de Vrisea gigantea Gandichaud, 1846 (Bromeliaceae) teve-se a oportunidade de coletar machos e fềmeas de um salticídeo que, ao ser identificado, verificou-se pertencer à espécie Asaphobelis physonychus Simon, 1902. Da análise da bibliografia constatou-se que o último trabalho enfocando esta espécie foi feito por GALIANO (1963) ao publicar uma extensa obra, na qual redescreveu os tipos das espécies americanas de Salticidae, descritas por Eugene Simon. Constatou-se, também, que a fêmea desta espécie ainda é desconhecida para a ciência, o que motivou a realização do presente trabalho. Para o macho, acrescenta-se as medidas referentes a quatro espécimes e a ilustração do palpo.

\section{MATERIAL E MÉTODOS}

Os espécimes encontram-se depositados na Coleção Aracnológica do $\mathrm{Mu}$ seu de Ciências da Pontifícia Universidade Católica do Rio Grande do Sul (MCP). As medidas são expressas em milímetros.

\section{Asaphobelis physonychus Simon, 1902 \\ Figs 1-8}

Asaphohelis physonychus, Sinkn. 1902: 384: lectótipo macho Brasil, Museum National d'Histoire Naturelle. Paris (MNHN) |não examinadol: Simon. 1903: 780. Fig. 932a, 782, 789, 801; Petrunkevitch, 1911: 549 (cat.): Petrunkevitch, 1928: 188: Bonnet, 1955: 758 (cat.): Roewer. 1954: 994 (cat.): Galiano, 1963: 297-8, lam. VIII, figs 1-4.

Descrição. Fêmea. Carapaça amarela. Área cefálica castanha. Olhos orla-

1) Instituto de Biociências. Pontifícia Universidade Católica do Rio Grande do Sul, Av. Ipiranga 6681. prédio 12, sala 216. 90619-900 Porto Alegre. Rio Grande do Sul, Brasil.

2) Bolsista de Íniciaçào Científica da FAPERGS 

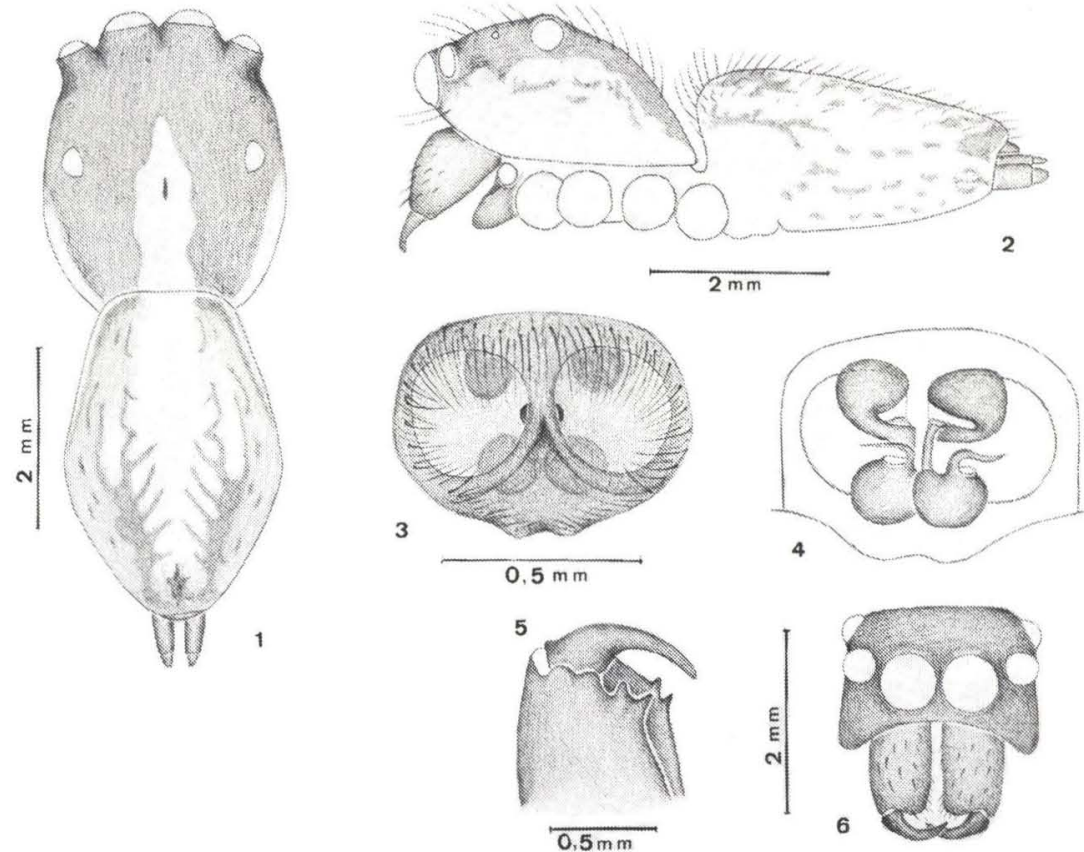

Figs 1-6. Asaphobelis physonycus fêmea. (1) Vista dorsal; (2) vista ventral: (3) epigino, vista ventral; (4) epigino vista dorsal; (5) quelícera, vista posterior; (6) cefalotórax, vista frontal.

dos de negro. Abdômen de dorso pardo com uma larga faixa longitudinal, mediana, amarela, percorrida por duas estreitas faixas paralelas, de pêlos avermelhados. $\mathrm{Na}$ porção apical ocorrem três ou quatro faixas transversais, em forma de acento circunflexo, cobertas por pêlos mais escuros. Laterais e ventre amarelos salpicados de pequenas manchas pardas das quais emergem pêlos negros (Figs 1-2). Pernas de fêmures amarelos sombreados de pardo com tufos de pêlos negros, dorsais.

Comprimento total 6,37. Carapaça, comprimento 3,06, largura 2,49, altura 1,60. Abdômen, comprimento 3,57, largura 2,55, altura 1,83. Comprimento relativo das perna 4-3-1-2. Perna I. fềmur 2,04, patela 1,14 , tíbia 1,42, metatarso 1,30, tarso 0,68 , total 6,58 . II. 1,76, 1,08, 1,14, 1,24, 0,58, total 5,80. III. 2,17, $1,00,1,30,1,55,0,77$, total 6,79 . IV. $2,38,1,08,1,70,1,86,0,77$, total 7,79. Espinulação: pernas I. Fêmur d1-1-1, p2a, v2a; patela p1, r1 medianos; tíbia p1, r1, v2-2-2, 1-1-1 macrocerdas dorsais; metatarso v2-2-2-2. II. Fêmur d1-1-1, p2a, r2a; patela p1, rl medianos; tíbia p1-1-1, r1-1, v2-2-2, 1-1-1 macrocerdas dorsais; metatarso p1, v2-2-2. III. Fêmur como em I e II; patela como em I e II e com 1-1-1 macrocerdas dorsais; tíbia d1, p1-1-1, r1-1-1, v2-2 e uma macrocerda dorsal apical; metatarso p1-1, r1-1, v2-2, pd1-1. IV. Fêmur, patela e tíbia como em I e II, metatarso p1-1, r1-1, v2-2, pd1-1.

Quelíceras amarelas, garra fulva, margem anterior do sulco ungueal com dois dentes e margem posterior com uma carena bidenteada (Fig. 5), comprimento 

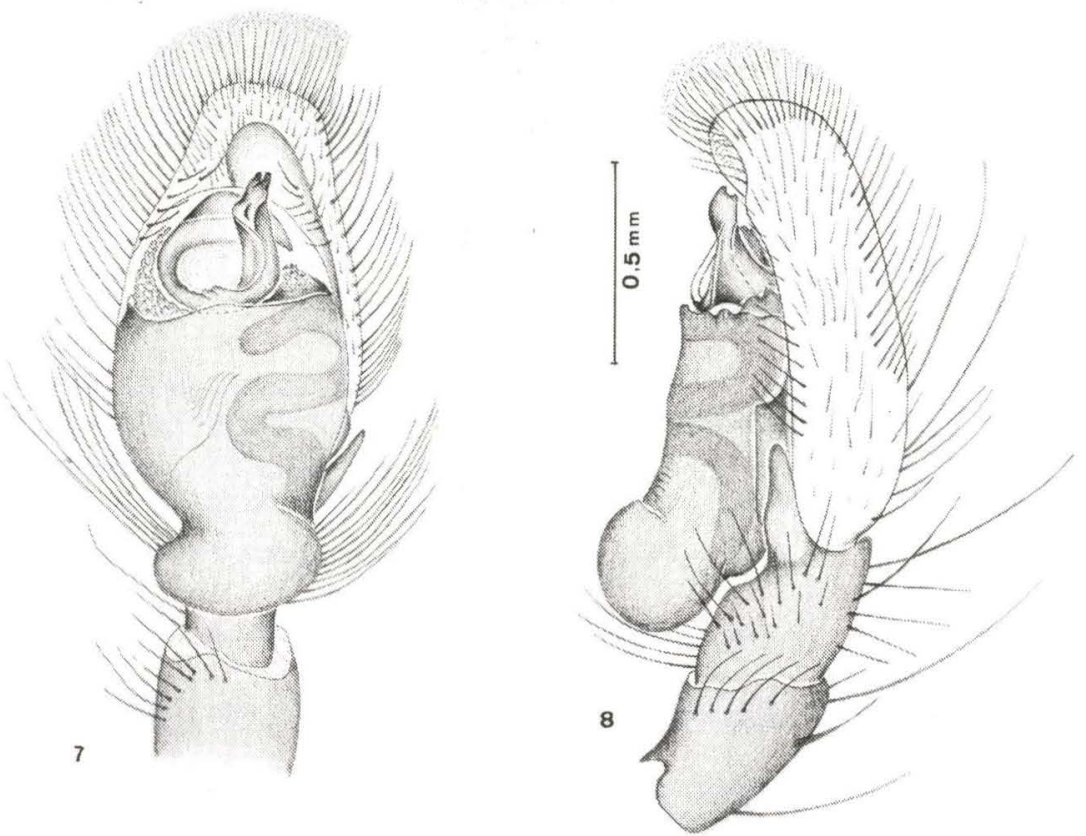

Figs 7-8. Asaphobelis physonycus macho. (7) Palpo, vista ventral: (8; palpo, vista retrolateral.

1,08, largura 0,71. Lábio amarelo, sombreado de fusco, comprimento 0,50, largura 0,56. Endites amarelas com densa escópula promarginal, apical, comprimento 0,90, largura 0,60. Esterno amarelo, convexo, cerdoso, comprimento 1,34, largura 1,06. Epigino constituído por duas depressões circulares separadas por um septo mediano, mais espessado na porção posterior (Figs 3-4).

Diâmetro dos olhos e interdistâncias: OMA 0,60, OLA 0,36, OMP 0,08, OLP 0,48, OLA-OMP 0,46, OMP-OLP 0,36. Área ocular: comprimento 1,46, largura da fila anterior de olhos 2,07 da fila posterior 2,07.

Variação. Sete fềmeas. Comprimento total $6,47-7,13$; carapaça: comprimento 3,07-3,32, largura 2,49-2,65; abdômen: comprimento 3,40-4,15, largura 2,40-2,98.

Macho. Conforme redescrito por GALIANO (1963). É muito semelhante à fêmea em todos os aspectos de forma e cor.

Acrescenta-se o desenho do palpo em vista ventral e retrolateral (Figs 7-8).

Variação. Sete machos. Comprimento total 5,47-8,30; carapaça: comprimento 2,73-3,98, largura 1,99-3,15; abdômen: comprimento 2,73-4,56, largura $1,58-2,90$.

Distribuição geográfica. BRASIL, Minas Gerais: Caraça; Rio Grande do Sul: Guaiba, Porto Alegre, Viamão. 
Material examinado. BRAsIL, Rio Grande do Sul: Porto Alegre (Lami), um macho, MCP 1286, 28.IV.1991, D. Picada leg.; um macho, MCP 410, V.1991, D. Picada leg.; Viamão, um macho, MCP 3651, 18.IV.1992, C.G. Mancio leg.; Guaiba, seis fềmeas, quatro machos MCP 3650, 16-18.VII.1993, A. Braul Júnior leg.

\section{REFERÊNCIAS BIBLIOGRÁFICAS}

Bonnet, P. 1955. Bibliographia Araneorum. Toulouse, Douladoure, parte 1, vol. 2, p. 1-918.

GALIANO, M.E. 1963. Las especies amareicanas de aranas de la familia Salticidae descriptas por Eugene Simon. Physis, Buenos Aires, 23 (66): 273-470.

PetrunkeVitch, A. 1911. A synonymic index-catalogue of the spiders of North, Central and South America with all adjacent islands, Greenland, Bermuda, West Indies, Terra del Fuego, Galapagos, etc... Bull. amer. Mus. nat. Hist. 29: $1-790$.

- 1928. Systema Araneorum. Trans, Connect, Acad. Arts Sci., New Haven, 29: 1-270.

RoEwer, C.F. 1954. Katalog der Araneae von 1758 bis 1940. Bremen, vol. 2b, p. $927-1751$.

SimON, E. 1903. Histoire Naturelle des Araigneés. Paris, Librairie Encyclopèdique de Roret, 2 (4): 669-1080.

Recebido em 18.I.1993; aceito em 21.IV.1994 